\title{
Stereoscopic vision in macular telangiectasia type 2
}

Simone Müller, $\mathrm{MD}^{1 *}$, Tjebo F.C. Heeren, $\mathrm{MD}^{1,2}$, Jennifer Nadal ${ }^{3}$, Peter Charbel Issa, MD, DPhil ${ }^{4}$, Philipp Herrmann, MD, PhD ${ }^{1}$, Frank G. Holz, MD Bettina K. Wabbels, MD ${ }^{1}$

1 Department of Ophthalmology, University of Bonn, Bonn, Germany Moorfields Eye Hospital NHS Foundation Trust, London, UK Institute of Medical Biometry, Informatics and Epidemiology, University Hospital of Bonn, Bonn, Germany

4 Oxford Eye Hospital, Oxford University Hospitals NHS Foundation Trust, and Nuffield Laboratory of Ophthalmology, Department of Clinical Neurosciences, University of Oxford, Oxford, UK

Short title: Stereoscopic vision in MacTel type 2

Conflict of Interest: None of the authors has a proprietary interest in this work.

Support: This work was supported by the Lowy Medical Research Institute, La Jolla, USA; Pro Retina, Bonn, Germany and the National Institute for Health Research (NIHR) Oxford Biomedical Research Centre (BRC), Oxford, UK.

* Corresponding author:

Simone Müller

Ernst-Abbe-Str. 2

53127 Bonn

Germany

E-Mail: simone.mueller@ukbonn.de

Tel.: +49 228-287-13253 
Müller et al.: Stereoscopic vision in MacTel type 2

\section{Key words:}

1. Macular telangiectasia type 2

2. MacTel type 2

3. Stereoscopic vision

4. Paracentral scotoma

5. Microperimetry 


\section{Abstract}

Purpose: To investigate stereoscopic vision in patients with macular telangiectasia type 2 and correlate a paracentral sensitivity loss to reduced stereoscopic function.

Methods: In a prospective single-center study, 50 patients with macular telangiectasia type 2 and 25 age-matched controls were investigated. Stereoscopic function was evaluated with Lang I, Titmus and TNO-test. Sensitivity of the central $16^{\circ}$ was tested using fundus-controlled perimetry (microperimetry). Functional loss was quantified as depth, size and localization of scotomata.

Results: Both Titmus and TNO-test revealed significantly reduced stereoscopic vision in patients compared to controls (both, $\mathrm{p}<0.0001$ ). This applied even to patients with only relative or monocular paracentral scotomata. A strong correlation was observed for reduced stereoscopic vision with horizontal scotoma size and with the distance of scotomata from the foveal center.

Conclusions: The results indicate that stereoscopic vision is impaired early in patients with MacTel type 2. A paracentral sensitivity loss, even if mild and limited to one eye, may considerably interfere with stereoscopic function despite normal visual acuity. Projection of paracentral scotomata within the patient's central visual field plays an important role in stereoscopic vision and should be considered when interpreting stereoscopic test results. 
Müller et al.: Stereoscopic vision in MacTel type 2

Macular telangiectasia (MacTel) type 2 is a bilateral retinal disease with structural and functional alterations that are usually most pronounced in the temporal parafovea. The disease commonly presents with characteristic findings in funduscopy and multimodal imaging.[1] Although the exact pathophysiology is not yet fully understood, recent findings point towards a multifactorial and complex disease, where a genetic predisposition as well as environmental factors may play a role.[2,3] Phenotypic observations have led to the hypothesis of a neurodegenerative disease with additional vascular alterations.[1,4]

First symptoms usually include reading difficulties or metamorphopsia, which most commonly occur in the sixth and seventh decade of life.[5] Reading difficulties were shown to be associated with paracentral scotomata that can be visualized by fundus controlled perimetry (microperimetry).[6-8] Microperimetry enables an accurate examination of position, size and depth of central and paracentral scotomata and shows a good functional correlation to morphological changes in MacTel.[9-13]

Scotomata within the central visual field are characteristic findings in MacTel, but may also occur within the scope of other retinal diseases such as central serous chorioretinopathy[14], diabetic retinopathy[15], macular holes, or age related macular degeneration[16-19]. In MacTel, however, scotomata are different with a typically bilateral and often symmetrical occurrence in the temporal paracentral retina. Usually, the foveola is spared, thus resulting in a preserved central visual acuity.[7,9] In the patient's central visual field, scotomata are typically and primarily projected nasally to the point of fixation $[7,9,20]$ (Figure 1 ), which seems to distinguish functional loss in MacTel from most other diseases. 
Müller et al.: Stereoscopic vision in MacTel type 2

Stereopsis is defined as binocular perception of relative depth that results of horizontal image disparities and is usually measured as stereoacuity (SA) in seconds of $\operatorname{arc}(\mathrm{ArcSec}) .[21]$ Abnormal binocular function and thus impaired stereoscopic vision can be observed in various ocular diseases including amblyopia[22,23], strabismus[24] and anisometropia.[25] Previously, a reduced stereoscopic function was also shown in patients with central scotomata in one eye resulting from retinal diseases.[16,26]

The influence of paracentral scotomata on stereoscopic vision, however, has not been investigated so far.

The underlying hypothesis of the present project was that in MacTel due to the occurrence of paracentral scotomata, visual information projected within a dysfunctional retinal sector (temporal parafovea) of one eye is projected on functioning retina (nasal retina) in the fellow eye (see fig. 1). Visual information projected in this sector is reduced to one eye and thus spatial information gets lost for this particular area leading to a disrupted processing of lateral disparity, a loss of binocularity and thus impaired depth perception. Figure 1 schematically shows the projection of bilateral scotomata within a patient's central visual field and within the Panum`s area. This assumption is anecdotally supported by patients with MacTel reporting difficulties in estimating distances, a symptom that typically occurs in the scope of an impaired depth perception.

We therefore systematically analyzed stereoscopic function and its correlation with paracentral scotomata in MacTel patients. Patients with and without absolute scotomata in microperimetry in one or both eyes were included in this analysis. 
Müller et al.: Stereoscopic vision in MacTel type 2

\section{Methods}

In this single-center cross-sectional study, the diagnosis of MacTel type 2 was based on characteristic findings in funduscopy, spectral-domain optical coherence tomography (SD-OCT), macular pigment distribution, and fluorescein angiography.[1] Patients of the MacTel natural history and observation study (NHOS) were recruited from a single center cohort at the Department of Ophthalmology, University of Bonn, Germany. Protocol details of the NHOS have been published previously.[27]

The study was approved by the Ethics Committee of the University of Bonn, was in adherence to the tenets of the Declaration of Helsinki, and patients and controls provided informed consent. Consecutive patients who presented to our department for their registration visit or annual follow up visit and who fulfilled the following criteria were asked to participate in this study. Inclusion criteria for patients were a clinical diagnosis of MacTel, a stable, foveal fixation and the absence of central fibrosis or secondary neovascularizations. Exclusion criteria were the presence of amblyopia, strabismus, a manifest or latent nystagmus and extrafoveal or unstable fixation. In addition to the NHOS standard protocol, microperimetry was performed on both eyes (MP1, Nidek Technologies, Padua, Italy) as described previously[7]. Under mesopic room illumination, a test grid with 83 test stimuli (Goldmann size III, 4-2 strategy, $1.27 \mathrm{~cd} / \mathrm{m}^{2}$ background illumination, stimulation time $100 \mathrm{~ms}$ ) with a stimulus intensity ranging from 0 to $20 \mathrm{~dB}$ was applied within the central $8^{\circ}$ of fixation. $\mathrm{A}$ fixation target (red cross, $2^{\circ}$ size) was provided. Depth of scotomata was categorized into absolute $(A)$ and relative $(R)$ (defined by retinal sensitivity of $\angle 0 \mathrm{~dB}(A)$ and $\geq 0$ to $\leq 12 \mathrm{~dB}(\mathrm{R})$, respectively, according to Chen et al[28,29]). Scotoma extension was 
Müller et al.: Stereoscopic vision in MacTel type 2

measured by maximal horizontal and vertical size (maximal diameter in degrees) and total scotoma surface area. For calculation of correlation coefficients, additive scotoma size of both eyes as well as monocular scotoma size of the worse eye were taken into account. Furthermore, we measured the localization of the scotoma in relation to the foveola. In this regard, for calculating correlation coefficients only the worse eye (with scotoma closer to the foveola) was considered.

Patients were divided into groups according to the occurrence of relative and/ or absolute scotomata: Group 00: No detectable scotoma in neither eye. Group R0: A relative scotoma in one eye $(R)$ and no scotoma $(0)$ in the other eye. Group RR: A relative scotoma in both eyes. Group A0: an absolute scotoma $(A)$ in one, but no scotoma in the other eye. Group AR: An absolute scotoma in one eye and a relative scotoma in the other eye. Group AA: Absolute scotomata in both eyes.

For stereoscopic testing, different tests are commercially available. Clinically, stereopsis is assessed commonly using contour stereograms that contain highcontrast stimuli (e.g. utilizing polarizing filters/ images) for measuring local stereopsis and random-dot based stereo tests for measuring global stereopsis. Local stereopsis enables horizontally disparate stimuli to serve as depth cues.[30,31] Global stereopsis terms the evaluation and correlation of sets of disparate and corresponding points over a larger retinal area.[32,33] We chose two quantitative and robust stereo tests for evaluating near stereoscopic function in patients and controls. Local stereopsis was measured with the Titmus contour stereo test, global stereopsis with the TNO random dot stereo test. Additionally, previous to quantitative testing, Lang I test was performed as semi-quantitative random dot screening test.

Bagolini test was performed prior to stereoscopic testing as qualitative assessment of simultaneous vision and fusion and in order to exclude monocular suppression.[34] 7 
Müller et al.: Stereoscopic vision in MacTel type 2

Table 1 gives an overview over the stereoscopic tests that were performed in this study. All tests were performed at a test distance of $40 \mathrm{~cm}$ with best corrected refraction for this distance and according to the manufacturer`s instructions.

Contrast sensitivity testing was performed with Pelli Robson Contrast sensitivity charts[35] under photopic conditions (mean room illumination: 100 lux). As a summation of monocular contrast sensitivity can be observed in binocular contrast vision[36,37], the test was conducted both monocularly and binocularly at a test distance of $1 \mathrm{~m}$ and with best refractive correction for the test distance. In order to avoid memorization, different test panels were used for each eye.

\section{Statistical analysis}

Statistical analysis was performed using the software environment R (version 3.2.3, The R Foundation for Statistical Computing, Vienna, Austria).

Continuous variables were described by using the mean \pm standard deviation and categorical variables were analyzed using frequency tables. Spearman correlation analyses were carried out in order to illustrate the relationships between stereoscopic test results and scotoma characteristics. A p-value $<0.05$ was considered significant. 
Müller et al.: Stereoscopic vision in MacTel type 2

\section{Results}

Fifty patients (24 males, 26 females) with a mean age of 62.3 years $( \pm S D 6.6$; range: 53-76) and 25 age-related controls (12 males, 13 females, mean age 61.7 years \pm SD 5.0, range 51-70) were included in the study. All participants showed a positive Bagolini test, indicating simultaneous vision and fusion as prerequisite for stereoscopic vision[34]. Mean best corrected binocular distant visual acuity was 0.11 logMAR (20/25 Snellen ( \pm SD 0.16 logMAR; range 0.6 to -0.2 logMAR)) in patients and $0.0 \log M A R(20 / 20$ Snellen ( \pm SD $0.07 \log M A R$; range 0.2 to $-0.2 \log M A R)$ in controls. Mean best corrected monocular visual acuity was $0.24 \log$ MAR in patients (20/32 Snellen ( \pm SD 0.26 logMAR; range 0.7 to $-0.2 \log M A R)$ and $0.04 \log M A R$ (20/20 Snellen ( \pm SD 0.09 logMAR; range 0.2 to -0.2 logMAR) in controls. Contrast sensitivity measurement revealed similar thresholds for patients and controls: mean monocular contrast sensitivity was $1.64 \log$ MAR ( \pm SD 0.21 ; range 1.05 to 1.95$)$ in patients and $1.67 \log$ MAR $( \pm S D 0.1$, range 1.5 to 1.95$)$ in controls. Mean binocular contrast sensitivity was $1.85 \log M A R( \pm S D$ 0.18; range 1.35 to 1.95 ) in patients and $1.87 \log M A R( \pm S D 0.1$, range 1.65 to 1.95$)$ in controls. Controls had normal retinal function on microperimetry testing.

\section{Stereoscopic vision:}

Stereoscopic vision was significantly decreased in patients with MacTel compared to age related controls $(p<0.0001)$. Both random dot stereo tests (TNO, Lang test) and contour stereo test (Titmus) revealed reduced stereoscopic function in patients with relative and/ or absolute scotomata (Fig. 2). A subgroup analysis according to monocular/ binocular presence of a relative or absolute scotoma (Fig. 2-B, -D) showed decreased stereoscopic function even in patients with monocular scotoma only (A0 group) and in patients with relative scotomata only (RR group). The only 
Müller et al.: Stereoscopic vision in MacTel type 2

patient with normal microperimetry in both eyes showed an intact stereoscopic function (not shown in Fig. 2-B and -D).

In contrast to patients with absolute scotomata, patients with relative scotomata achieved worse results in TNO test compared to Titmus test $\left({ }^{* * *} \mathrm{p}<0.001\right.$, data not shown). Lang test I was negative (i.e. no object seen) in 32 out of 50 patients (64\%). Only 18 out of 50 patients (36\%) were able to identify one or two out of three objects. 13 of these patients were from group $R 0$ (3/13) and RR (10/13). 3 patients were from group A0. All controls $(n=25)$ were able to see all 3 test objects.

Central visual acuity, contrast sensitivity and stereoscopic function

Contrast sensitivity was similar in patients and controls both under monocular and under binocular testing conditions (see above). Patients did not exhibit significant interocular differences between right and left eye (Wilcoxon matched-pairs signed rank test: $p=0.88)$. Central visual acuity was significantly correlated to contrast sensitivity (Spearman correlation coefficient: $r=0.50, p<0.01$ ), but not to stereoscopic function ( $r=0.10$ (TNO) and $r=0.19$ (Titmus), respectively, both $p>0.05)$. Figure 4 shows the high interindividual variability and elevation of stereothresholds that we observed in our patient cohort despite of a mainly preserved visual acuity.

\section{Correlation of stereoscopic vision with scotoma characteristics}

Horizontal scotoma size was strongly correlated to both TNO and Titmus test results (Spearman correlation coefficient for absolute scotomata (additive value for both eyes) $r=0.64$ (TNO) and 0.75 (Titmus), respectively). Vertical scotoma size and total scotoma surface area were both significantly associated with TNO and Titmus test results (Spearman correlation coefficient for absolute scotomata (additive value for both eyes): vertical size: $r=0.53$ (TNO) and 0.60 (Titmus); surface area: $r=0.49$ (TNO) 
Müller et al.: Stereoscopic vision in MacTel type 2

and 0.47 (Titmus), data not shown). We did not observe a significant difference between the correlation coefficients considering the values of both eyes and the worse eye only (data not shown).

Both TNO and Titmus test results showed a negative, significant correlation with distance of the scotomata to the foveola (Spearman correlation $r=-0.61, p<0.0001$ and $r=-0.59, p<0.0001$ respectively). In Titmus test, a sharp functional decrease was observed when scotomata approached the foveola $\leq 1^{\circ}$. Patients showing scotomata located $\leq 0.5^{\circ}$ to the foveola were only capable of passing the Titmus screening test (Titmus fly positive, ca. 3500 seconds of arc).

\section{Discussion}

Stereoscopic function is early impaired in MacTel and is associated with paracentral sensitivity loss

A loss of paracentral sensitivity resulting in relative and absolute scotomata is a typical finding in MacTel type 2 and often occurs bilaterally.[7] In this study, we showed that this sensitivity loss was significantly correlated with an impairment of stereoscopic function. This seemed to be the case even for patients with early disease stages in one or both eyes who showed preserved retinal sensitivity in one eye ( $n=9$; yet with significance only reached for the A0 subgroup, presumably due to low numbers) and/or only a relative reduction of sensitivity. The only patient without any sensitivity loss showed no impairment in stereoscopic function.

Of note, these phenomena were observed in spite of a mainly preserved central visual acuity. Out of our total patient cohort, only 6/50 patients had a unilateral VA of $\geq 0.5 \log$ MAR $(\leq 20 / 63$ Snellen (range 0.5-0.7 logMAR)) in their worse eye and 43/50 patients had a binocular VA of $\leq 0.2 \operatorname{logMAR}(\geq 20 / 32$ Snellen). Although previous 
Müller et al.: Stereoscopic vision in MacTel type 2

studies indicated some association between visual acuity and stereoacuity, a direct correlation has never been documented.[38,39] It was shown that good stereo test results (up to 40 seconds of arc in Titmus test) may even be achieved when visual acuity is reduced to $20 / 200$ on both eyes.[40,41] Simons and Reinecke noted that amblyopic patients were able to achieve test results up to $140 \mathrm{ArcSec}$ in Titmus test with monocular visual acuity of $\leq 20 / 300$ in their worse eye[42]. Levy and Glick found that normal probands with artificially reduced visual acuity of $<20 / 40$ in their worse eye achieved test results of up to 40 ArcSec in Titmus test. At a monocular visual acuity of 20/200, mean stereoacuity was 160 ArcSec in these probands.[39] In a later study including both probands with experimental and organic amblyopia, Goodwin and Romano demonstrated mean values of 378 ArcSec in Titmus test for patients with experimental monocular amblyopia of 20/40, 136 ArcSec for patients with experimental binocular amblyopia of $20 / 40$ and similar or even better values for patients with organic amblyopia and equivalent visual acuity. In their experiments, a visual acuity threshold of $20 / 40$ or better was necessary in order to achieve stereothresholds $\leq 40$ ArcSec. [22] In our study, however, patients with a visual acuity of their worse eye of $20 / 40$ or better averaged much higher stereothresholds of 737 ArcSec. In a subgroup of patients with a completely preserved visual acuity (VA of their worse eye of $0.1 \log M A R(20 / 25)$ or better; $n=16)$ and normal contrast sensitivity (mean values: monocular 1.81 logMAR, binocular 1.95 logMAR), stereothresholds in Titmus test averaged 866 ArcSec (see figure 4-B). Thus, a mere reduction of visual acuity cannot account for the marked decrease in stereoacuity that we observed in our patients.

Contrast sensitivity measures the ability to discern between luminances of different levels in a static image. In binocular vision, a summation of monocular contrast 
Müller et al.: Stereoscopic vision in MacTel type 2

sensitivity can be observed.[36,37] Previously, it was proposed that stereothresholds are elevated by binocular suppression caused by interocular differences in contrast vision.[43-46] This was even the case, when interocular differences were as small as 50-25\%.[47] However, in our patient cohort, interocular differences in contrast sensitivity averaged below $10 \%$ in patients. Overall, under photopic conditions, we did not note a significant difference in contrast sensitivity between patients and controls.

In conclusion, neither a decrease of visual acuity nor of contrast sensitivity nor interocular differences may explain the distinct reduction of stereoscopic function, that we found in patients with MacTel.

Scotoma size and projection is crucial for stereoscopic function and should be considered when interpreting stereoscopic test results.

In this analysis, stereoscopic function decreased with scotoma size and proximity of scotomata to the foveal center. However, differences between the conducted stereo tests were observed as follows: In Titmus test, we noted a sharp decrease of stereoscopic function in patients with scotomata approaching the foveola $<1^{\circ}$. This observation may be explained by the projection of an individual`s scotomata in the central visual field, on the fixated test object and its contours.

In Titmus test, at a test distance of $40 \mathrm{~cm}$, the visual angle $\alpha$ of one single Titmus ring is $1.15^{\circ}$. For complete perception of each single ring, a scotoma free area of $0.57^{\circ}$ from the foveal center is required for each eye. The simultaneous perception of all 4 Titmus rings within one test field is necessary to compare the rings and decide which one steps out of the picture. In order to achieve test results $<200 \mathrm{ArcSec}$ (higher 13 
Müller et al.: Stereoscopic vision in MacTel type 2

(false positive) results may be achieved with monocular vision[48]), a scotoma free area of at least $1.86^{\circ}$ from the foveola would be required in each eye.

In TNO test, test objects are larger: One test circle has a visual angle of $8.8^{\circ}$, while the opening of the circle has a visual angle of $4.4^{\circ}$. Scotomata that were projected at either the object borders or within the opening of the circle comprised an obstacle to the detection of the opening of the circle for patients. However, patients described seeing parts of the circles distorted or even missing.

In Lang I test, the majority of our patients (62\%) were not able to identify any object. However, most patients were capable of localizing two to three objects on the test panel, but could not identify their shapes. Interestingly, patients were rather able to identify the car $\left(550 \mathrm{ArcSec}\right.$; size: $\left.10^{\circ}\right)$ than the cat $\left(1200 \mathrm{ArcSec}\right.$, size: $\left.4.8^{\circ}\right)$ or the star (600 ArcSec; size: $3.4^{\circ}$ ), indicating that the Lang test results rather seemed to depend on the size of the test object than on its horizontal disparity. Figure 3 shows a detailed overview over individual scotoma projection on different test panels and the according test results that patients achieved in TNO and Titmus test (fig. 3-B).

In general, in random dot stereo tests (TNO, Lang I) missing image information may overall have a greater influence on the test results than the horizontal disparity of the test objects. This may be due to the proportion and position of scotomata, especially in relation to the size of the test object, and, more importantly, due to the projection of scotomata at the contours of the test objects. This may also explain why patients with relative scotomata with good test results in Titmus test had a significantly worse outcome in TNO test. These observations are in accordance with the results of Friedburg et al[26], who suggested that a decreased density of local stereo information caused by a not sharply delimited paracentral scotoma interferes with Random dot test results. Moreover, our results are in line with the findings of Hirai et 14 
Müller et al.: Stereoscopic vision in MacTel type 2

al, who proposed that an intact central visual field of approximately $5^{\circ}$ to $6^{\circ}$ is necessary in order to maintain central stereopsis ${ }^{29}$, which exactly corresponds to the area that is typically affected in patients with MacTel.

Figure 5 illustrates different examples of scotoma projection (patient's view) within 0.5 to $5^{\circ}$ of the central visual field on different test panels.

In summary, in this study we are showing impaired stereo vision in patients with MacTel which seems to be associated with scotoma size and position, even if the scotoma is limited to one eye. To our knowledge, this is the first study showing an impaired stereoscopic vision as early functional deficit in patients with MacTel. Further studies are warranted in order to compare stereoscopic vision in MacTel with other macular diseases resulting in a monocular or binocular paracentral sensitivity loss. 


\section{References}

1 Charbel Issa P, Gillies MC, Chew EY, Bird AC, Heeren TF, Peto T, Holz FG, Scholl HP: Macular telangiectasia type 2. Prog Retin Eye Res 2013;34:49-77.

2 Scerri TS, Quaglieri A, Cai C, Zernant J, Matsunami N, Baird L, Scheppke L, Bonelli R, Yannuzzi LA, Friedlander M, Egan CA, Fruttiger M, Leppert M, Allikmets R, Bahlo M: Genome-wide analyses identify common variants associated with macular telangiectasia type 2. Nat Genet 2017;49:559-567. 3 Muller S, Allam JP, Bunzek CG, Clemons TE, Holz FG, Charbel Issa P: Sex Steroids and Macular Telangiectasia Type 2. Retina 2017

4 Charbel Issa P, Heeren TF, Kupitz EH, Holz FG, Berendschot TT: Very Early Disease Manifestations of Macular Telangiectasia Type 2. Retina 2016;36:524-534.

5 Heeren TF, Holz FG, Charbel Issa P: First symptoms and their age of onset in macular telangiectasia type 2. Retina 2014;34:916-919.

6 Finger RP, Charbel Issa P, Fimmers R, Holz FG, Rubin GS, Scholl HP: Reading performance is reduced by parafoveal scotomas in patients with macular telangiectasia type 2 . Invest Ophthalmol Vis Sci 2009;50:1366-1370.

7 Charbel Issa P, Helb HM, Rohrschneider K, Holz FG, Scholl HP: Microperimetric assessment of patients with type 2 idiopathic macular telangiectasia. Invest Ophthalmol Vis Sci 2007;48:3788-3795.

8 Trauzettel-Klosinski S: Reading disorders due to visual field defects: a neuro-ophthalmological view. Neuro-Ophthalmology 2002;27:79-90.

9 Heeren TF, Clemons T, Scholl HP, Bird AC, Holz FG, Charbel Issa P: Progression of Vision Loss in Macular Telangiectasia Type 2. Invest Ophthalmol Vis Sci 2015;56:3905-3912.

10 Sallo FB, Leung I, Mathenge W, Kyari F, Kuper H, Gilbert CE, Bird AC, Peto T, MacTel Study G: The prevalence of type 2 idiopathic macular telangiectasia in two African populations. Ophthalmic Epidemiol 2012;19:185-189.

11 Heeren TFC, Kitka D, Florea D, Clemons TE, Chew EY, Bird AC, Pauleikhoff D, Issa PC, Holz FG, Peto T: Longitudinal Correlation of Ellipsoid Zone Loss and Functional Loss in Macular Telangiectasia Type 2. Retina 2017

12 Charbel Issa P, Troeger E, Finger R, Holz FG, Wilke R, Scholl HP: Structure-function correlation of the human central retina. PLoS One 2010;5:e12864.

13 Mukherjee D, Lad EM, Vann RR, Jaffe SJ, Clemons TE, Friedlander M, Chew EY, Jaffe GJ, Farsiu S, MacTel Study G: Correlation Between Macular Integrity Assessment and Optical Coherence Tomography Imaging of Ellipsoid Zone in Macular Telangiectasia Type 2. Invest Ophthalmol Vis Sci 2017;58:BIO291-BIO299.

14 Chen H, Wu D, Huang S, Guan T, Liu C: [Microperimetry evaluation in central serous chorioretinopathy]. Yan Ke Xue Bao 2006;22:149-153.

15 Vujosevic S, Midena E, Pilotto E, Radin PP, Chiesa L, Cavarzeran F: Diabetic macular edema: correlation between microperimetry and optical coherence tomography findings. Invest Ophthalmol Vis Sci 2006;47:3044-3051.

16 Hirai T, Ito Y, Terasaki H, Ito M, Sato M, Miyake Y: Stereopsis in idiopathic macular hole with special reference to the size of the hole and its effect on stereoacuity. Binocul Vis Strabismus $Q$ 2003;18:242-248.

17 Mireskandari K, Garnham L, Sheard R, Ezra E, Gregor ZJ, Sloper JJ: A prospective study of the effect of a unilateral macular hole on sensory and motor binocular function and recovery following successful surgery. Br J Ophthalmol 2004;88:1320-1324.

18 Pilotto E, Guidolin F, Convento E, Spedicato L, Vujosevic S, Cavarzeran F, Midena E: Fundus autofluorescence and microperimetry in progressing geographic atrophy secondary to age-related macular degeneration. Br J Ophthalmol 2013;97:622-626.

19 Midena E, Radin PP, Pilotto E, Ghirlando A, Convento E, Varano M: Fixation pattern and macular sensitivity in eyes with subfoveal choroidal neovascularization secondary to age-related macular degeneration. A microperimetry study. Semin Ophthalmol 2004;19:55-61. 
20 Vujosevic S, Heeren TFC, Florea D, Leung I, Pauleikhoff D, Sallo F, Bird A, Peto T: SCOTOMA CHARACTERISTICS IN MACULAR TELANGIECTASIA TYPE 2: MacTel Project Report No. 7-The MacTel Research Group. Retina 2017

21 Ogle KN: Spatial localization and stereoscopic vision. New York, Hafner Publishing, 1964.

22 Goodwin RT, Romano PE: Stereoacuity degradation by experimental and real monocular and binocular amblyopia. Invest Ophthalmol Vis Sci 1985;26:917-923.

23 Fawcett SL, Herman WK, Alfieri CD, Castleberry KA, Parks MM, Birch EE: Stereoacuity and foveal fusion in adults with long-standing surgical monovision. J AAPOS 2001;5:342-347.

24 Read JC: Stereo vision and strabismus. Eye (Lond) 2015;29:214-224.

25 Levi DM, McKee SP, Movshon JA: Visual deficits in anisometropia. Vision Res 2011;51:48-57.

26 Friedburg D: [Stereoscopic vision with central scotomata (author's transl)]. Klin Monbl Augenheilkd 1981;178:85-88.

27 Clemons TE, Gillies MC, Chew EY, Bird AC, Peto T, Figueroa MJ, Harrington MW, MacTel Research G: Baseline characteristics of participants in the natural history study of macular telangiectasia (MacTel) MacTel Project Report No. 2. Ophthalmic Epidemiol 2010;17:66-73.

28 Rohrschneider K, Springer C, Bultmann S, Volcker HE: Microperimetry--comparison between the micro perimeter 1 and scanning laser ophthalmoscope--fundus perimetry. Am J Ophthalmol 2005;139:125-134.

29 Chen FK, Patel PJ, Xing W, Bunce C, Egan C, Tufail AT, Coffey PJ, Rubin GS, Da Cruz L: Testretest variability of microperimetry using the Nidek MP1 in patients with macular disease. Invest Ophthalmol Vis Sci 2009;50:3464-3472.

30 Mitchell DE, O'Hagan S: Accuracy of stereoscopic localization of small line segments that differ in size or orientation for the two eyes. Vision Res 1972;12:437-454.

31 Kertesz AE: Disparity detection within Panum's fusional areas. Vision Res 1973;13:1537-1543.

32 Westheimer G, McKee SP: Stereogram design for testing local stereopsis. Invest Ophthalmol Vis Sci 1980;19:802-809.

33 Mitchell DE: Qualitative depth localization with diplopic images of dissimilar shape. Vision Res 1969;9:991-994.

34 Bagolini B: [Technic for examination of binocular vision without introduction of dissociating elements: the striated glass test]. Boll Ocul 1958;37:195-209.

35 Pelli D RJ, Wilkins AJ. : The design of a new letter contrast chart for measuring contrast sensitivity. Clinical Vision Sciences 1988;2:187-199.

36 Legge GE: Binocular contrast summation--II. Quadratic summation. Vision Res 1984;24:385394.

37 Legge GE, Rubin GS: Binocular interactions in suprathreshold contrast perception. Percept Psychophys 1981;30:49-61.

38 Sitko KR, Peragallo JH, Bidot S, Biousse V, Newman NJ, Bruce BB: Pitfalls in the Use of Stereoacuity in the Diagnosis of Nonorganic Visual Loss. Ophthalmology 2016;123:198-202.

39 Levy NS, Glick EB: Stereoscopic perception and Snellen visual acuity. Am J Ophthalmol 1974;78:722-724.

40 Roggenkamper P: [Stereoscopic vision in reduced visual acuity]. Klin Monbl Augenheilkd 1983;183:105-109.

41 Colenbrander MC: The limits of stereoscopic vision. Ophthalmologica 1948;115:363.

42 Simons K, Reinecke RD: A reconsideration of amblyopia screening and stereopsis. Am J Ophthalmol 1974;78:707-713.

43 Marmor MF, Gawande A: Effect of visual blur on contrast sensitivity. Clinical implications. Ophthalmology 1988;95:139-143.

44 Anderson PA, Movshon JA: Binocular combination of contrast signals. Vision Res 1989;29:1115-1132.

45 Pardhan S: A comparison of binocular summation in young and older patients. Curr Eye Res 1996;15:315-319. 
Müller et al.: Stereoscopic vision in MacTel type 2

46 Oguz $\mathrm{H}$, Oguz V: The effects of experimentally induced anisometropia on stereopsis. J Pediatr Ophthalmol Strabismus 2000;37:214-218.

47 Schor C, Erickson P: Patterns of binocular suppression and accommodation in monovision. Am J Optom Physiol Opt 1988;65:853-861.

$48 \quad$ Fricke T, Siderov, J: Stereopsis, stereotests, and their relation to vision screening and clinical practice. Clinical and Experimental Optometry 1997;80:165-172. 
Müller et al.: Stereoscopic vision in MacTel type 2

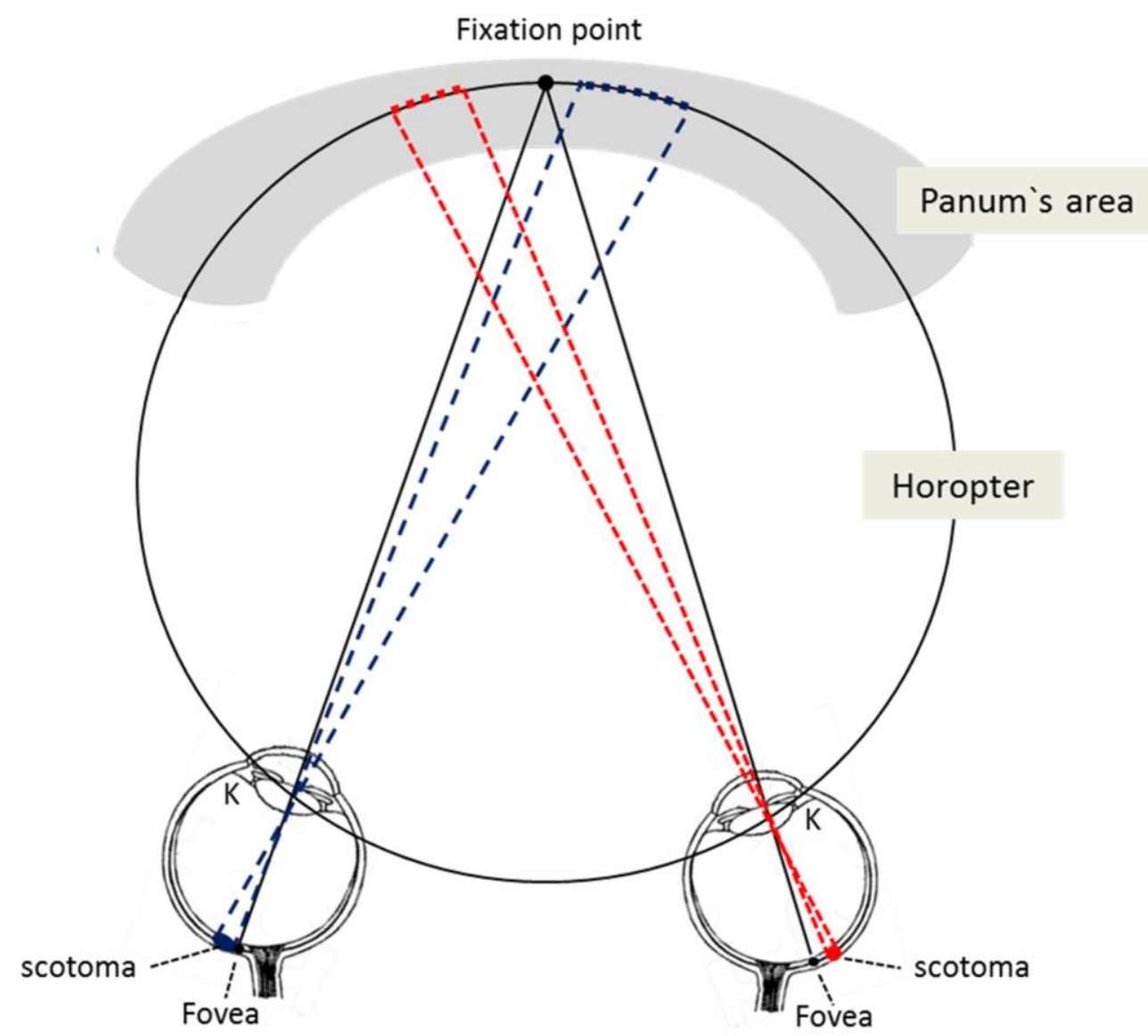

\section{Figure 1}

Schematic representation of asymmetric bilateral paracentral temporal scotomata and their projection in the patient's central visual field. Left eye: large scotoma located close to the foveola (blue); right eye: small scotoma with greater distance to the foveola (red). Both scotomata are projected within the Panum's area, leading to a loss of spatial information within these sectors due to absent retinal correspondence. Thereby the patient's stereoscopic perception is impaired. 
Müller et al.: Stereoscopic vision in MacTel type 2
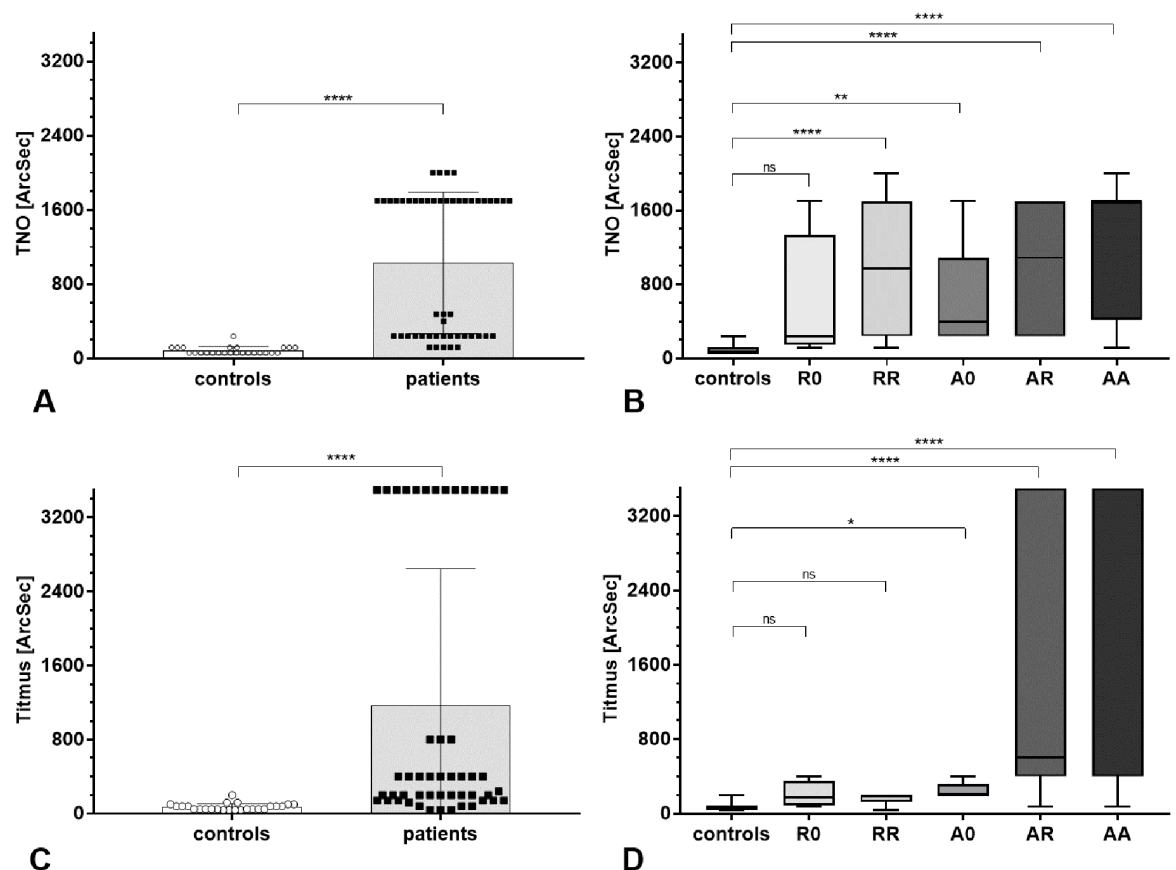

\section{Figure 2}

MacTel patients showed a significantly decreased stereoscopic function in both TNO and Titmus test compared to age-related controls (2-A and $-C$; controls: $n=25$, patients: $n=50$; both $\left.{ }^{* * * *} p<0.0001\right)$.

2-B, -D - Subgroup analysis for TNO-test (B) and Titmus test (D): controls: $n=25$; R0: $n=4 ; R R: n=12 ; A 0: n=5 ; A R: n=10 ; A A: n=18$. (Subgroup $00: n=1$ is not shown here).

Patients of all subgroups had overall decreased test results in both TNO and Titmus test compared to controls. However, significant differences were not observed for the R0 subgroup in both tests and for patients with relative scotomata only (RR) in Titmus test $(p=0.08) .{ }^{*} p<0.05 ;{ }^{* *} p<0.01 ;{ }^{* * *} p<0.0001$; ns: no significant difference.

Note the worse outcome in TNO compared to Titmus test for patients with relative scotomata only (R0 and RR-subgroups; Fig. 2-B, -D). 
Müller et al.: Stereoscopic vision in MacTel type 2

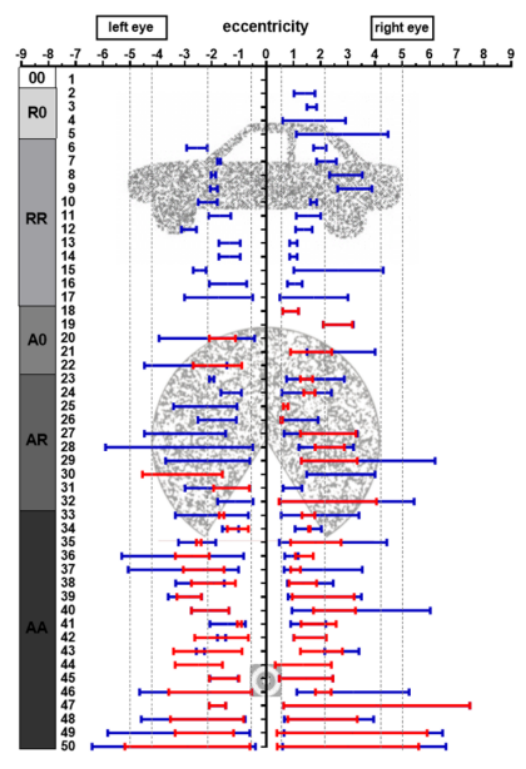

A

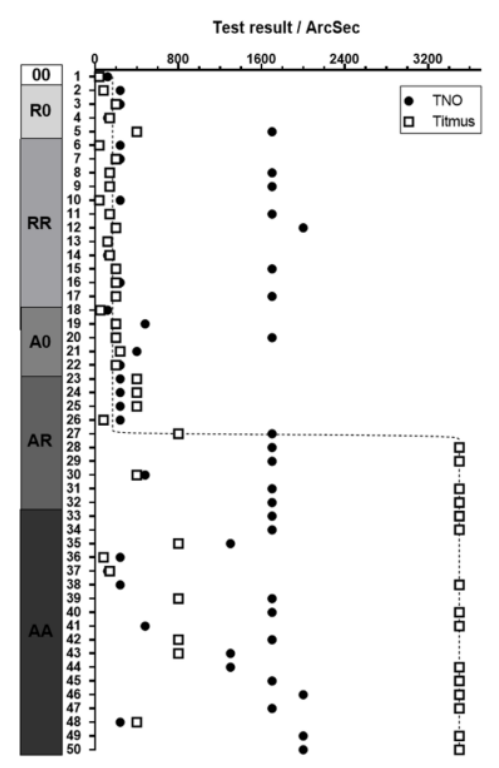

B

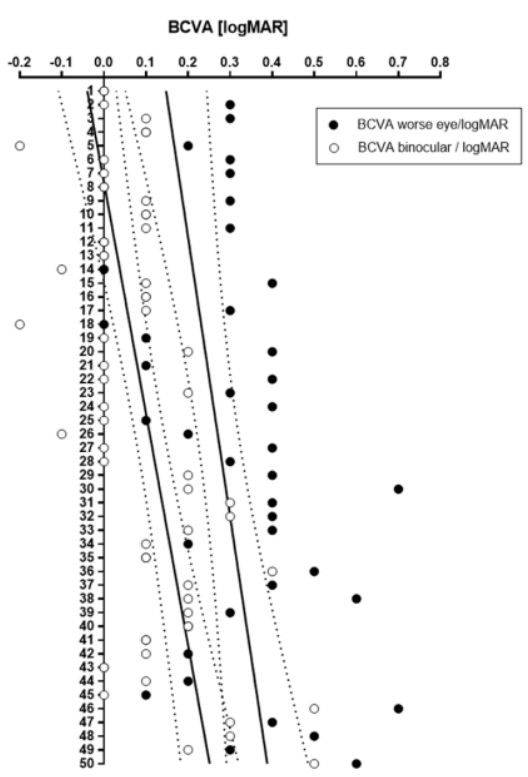

C

\section{Figure 3}

Projection of paracentral scotomata within the patient`s central visual field and respective to the contours of different test objects $(A)$ seems to be crucial for stereoscopic test outcome (B). $n=50$ patients, 100 eyes. Note the sharp decrease in stereoscopic function with bilateral occurrence of absolute and relative scotomata on both eyes (Figure 3-B, group AR), growing scotoma size and increasing proximity of scotoma to the foveal center (Figure 3-A).

A - Ranking according to size, position (respective to the foveola: $0^{\circ}$ eccentricity) and depth of scotomata (subgroups 00 to $A A$ ) in both eyes and projection of scotomata within the patient`s central visual field. Red: absolute scotomata, blue: relative scotomata.

$\mathrm{B}-$ Titmus and TNO test results achieved by patients of figure 3-A. 
Müller et al.: Stereoscopic vision in MacTel type 2

C - Visual acuity of both eyes (white dots) and the patient's worse eye (black dots), respectively, of patients of figure 3-A. Note the differing courses of the curves of visual acuity and stereoacuity (3-C and -B).

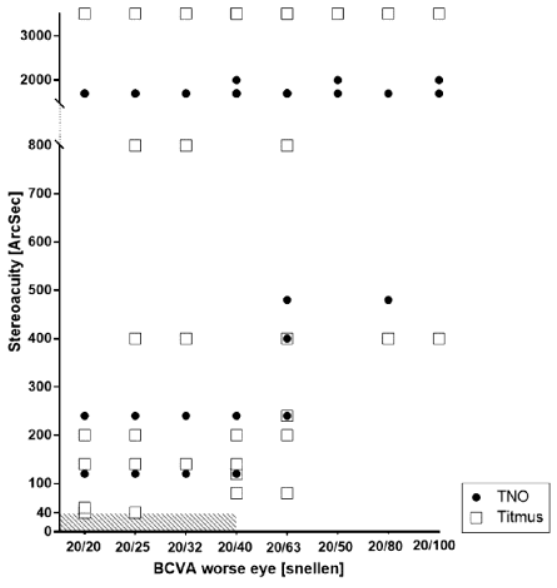

A

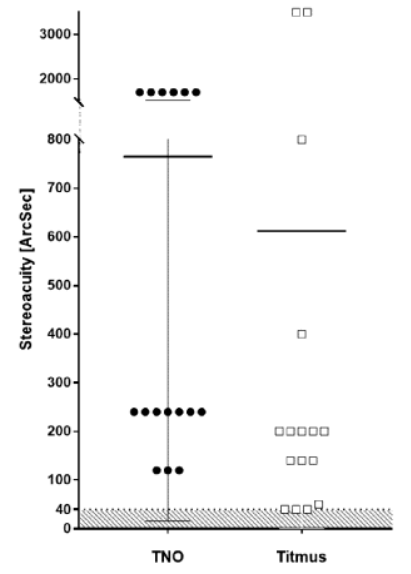

B

\section{Figure 4}

Despite of a mainly preserved visual acuity, elevated stereothresholds and a high interindividual variability of stereo test results were present in patients with MacTel.

A - Despite of an overall decrease of stereoacuity (SA) with loss of visual acuity (VA; monocular, worse eye), only a weak, not significant correlation between VA and SA was observed ( $n=50$; see text). In previous studies [22, 39], a visual acuity threshold of at least 20/40 (0.3 logMAR) in the worse eye was shown to be necessary in order to achieve stereo test results of $\leq 40$ ArcSec (shaded area).

B - Subgroup analysis of patients with normally preserved visual acuity (20/25 or better in the patients` worse eye) and normal contrast sensitivity ( $n=16)$. Note the decreased stereoacuity in these patients despite of normal visual acuity and normal contrast sensitivity. 
Müller et al.: Stereoscopic vision in MacTel type 2
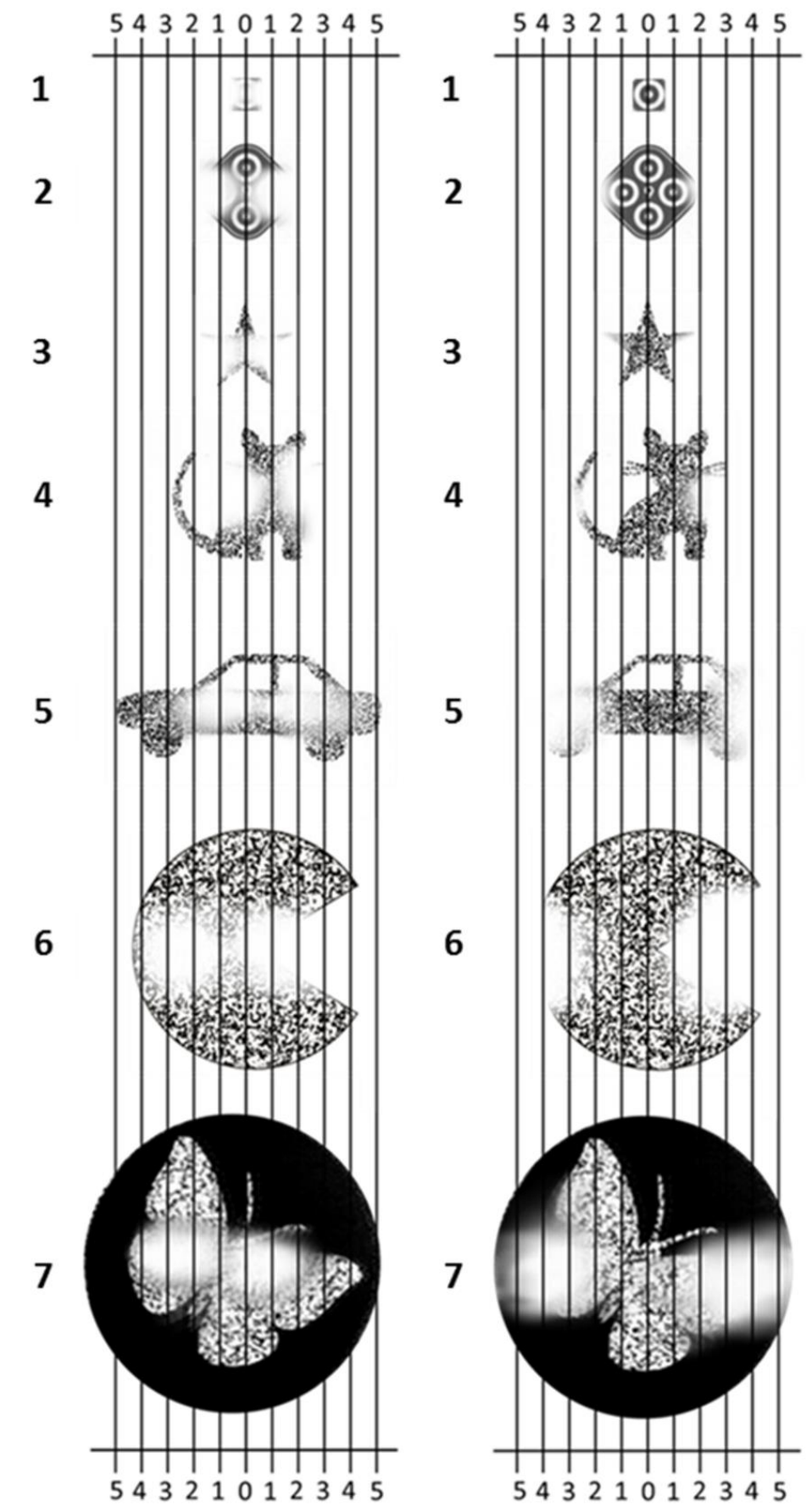

Eccentricity [retinal degrees] Eccentricity [retinal degrees]

A

B

\section{Figure 5}

Exemplary schematic representation of bilateral paracentral scotomata (lighter sectors with impaired depth perception due to monocular perception only) within the central visual field on Titmus, Lang I and TNO test panels: 
Müller et al.: Stereoscopic vision in MacTel type 2

5-A: between $0.5^{\circ}$ and $2^{\circ}$ and

5-B: between $2^{\circ}$ and $5^{\circ}$.

1-single Titmus ring; 2- test field with four Titmus rings; 3 - 5: Lang I test; 6-7: TNOtest.

Dependent on size, depth and location of scotomata as well as on size and horizontal disparity of the test object, the patient is not able to identify the contours and distinguish the shapes from the background. Note, that in this simplified representation, the patients fixate on the center of each target item.

\section{Table 1}

Stereoscopic tests and their characteristics

\begin{tabular}{|c|c|c|c|}
\hline Stereoscopic test & TNO & Titmus & Lang \\
\hline Testing of global/ local stereopsis & global & local & global \\
\hline Category of stereo testing & random dot & contour & random dot \\
\hline Screening test available & yes & yes & yes \\
\hline Limit of screening test [seconds of arc] & 1700 & 3500 & 600 \\
\hline Quantitative/ qualitative testing & quantitative & quantitative & semi-quantitative \\
\hline Range of horizontal disparity [seconds of arc] & 15 to 480 & 40 to 800 & 240 to 600 \\
\hline $\begin{array}{l}\text { Size of test objects (horizontal diameter } \\
\text { [degrees]) }\end{array}$ & 8.8 & 1.15 (single test ring) to 3.72 (test field) & 3.4 to 10 \\
\hline Examplary test object(s) & & & (1) \\
\hline
\end{tabular}

